\title{
Correction to: A multimodal imaging features of the brain in adult-onset neuronal intranuclear inclusion disease
}

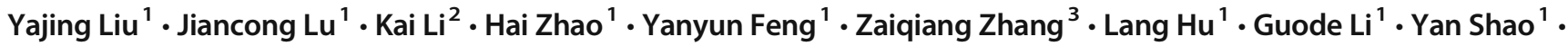 \\ Yukai Wang ${ }^{1}$
}

Published online: 26 February 2019

(C) Fondazione Società Italiana di Neurologia 2019

\section{Correction to: Neurological Sciences 2019}

$$
\text { https://doi.org/10.1007/s10072-019-03742-5 }
$$

In the original article, Zaiqiang Zhang was affiliated to Department of Neurology, Beijing Hospital, National Center of Gerontology, Beijing, China. The corrected affiliation should be: Department of Neurology, Beijing Tiantan Hospital, Capital Medical University, Beijing, China.

Publisher's note Springer Nature remains neutral with regard to jurisdictional claims in published maps and institutional affiliations.

The online version of the original article can be found at https://oi.org/ 10.1007/s10072-019-03742-5

Yan Shao

525770184@qq.com

Yukai Wang

525770184@qq.com

1 Department of Neurology, Foshan Hospital Affiliated to Sun Yat-sen University, No. 81, Lingnan North Road,

Foshan 528000, Guangdong, China

2 Department of Neurology, Beijing Hospital, National Center of Gerontology, Beijing, China

3 Department of Neurology, Beijing Tiantan Hospital, Capital Medical University, Beijing, China 